\title{
Velocity Characteristics around Short Continuous Helical Baffles Using PIV With and Without One Inner Tube
}

\author{
Tae Hyun Chang ${ }^{1}$, Chang-Hoan Lee ${ }^{2}$ \\ ${ }^{1}$ Senior Research Fellow of RESEAT, Korea Institute of Science and Technology Information, South \\ Korea \\ ${ }^{2}$ Korea Institute of Science and Technology Information, Deaejeon, South Korea
}

\begin{abstract}
Usually the shell and tube heat exchangers are used to recover the energy between fluids. Recently, a lot of papers are published about these kinds of heat exchangers, but it is very seldom to describe local velocity profiles or to compare the features of flowing with or without inner tubes in a horizontal circular tube.

Particle image velocimetry (PIV) method and a commercial program are employed to measure or to calculate the velocity profiles in the flow around continuous helical baffles. The results show that swirling flow is produced at the entry, between the helical baffle plates and the outlet of the baffles. The tangential components are so strong between the two helical baffles but the values of the axial or radial velocities components are very small along the distance.
\end{abstract}

Keywords: Helical baffle plate, Particle image velocimetry, Swirling flow, Shell and tube heat exchanger

\section{INTRODUCTION}

Heat exchangers have been widely employed, for example, chemical process, heat recovery system and a boiler feed water heating etc. in the industrial applications. For improving heat transfer at a heated surface, several methods include the techniques such as treated surface, rough surfaces, extended surfaces, coiled tube, displaced enhancement devices, vortex generator devices and additives to the fluids. Also twisted tape or helical plate is one of the main inserts which can improve heat transfer rat instead of the vertical plate in the shell and tube heat exchanger.

Gupta et al.[1] studied the effect of the number of helices with respect to baffle using baker yeast ad dodecane-water in a mineral membrane. They used a video camera for visualization test and their results are showed that rotational velocity increased the mixing and migration of the rejected particles. Van Dijk et al.[2] researched the physical behavior of a dense fluidized bed employing internals using X-rays. Their results are indicated that the bubble size and velocity are a function of the fluidization velocity.

Halfdan Knudsen et al.[3] investigated a helical flow in a shell and tube heat exchanger using a designed pitot tube for $\mathrm{Re}=7000-18000$. Authors are developed a separated flow model base on their experimental results. About several years late, Young-Seok Son et al.[4] simulated a shell and tube heat exchanger with spiral baffle plates using a commercial thermal-fluid analysis code, CFX4.2. The results are showed that spiral baffle plates induced vortices in the shell side flow field and enhanced heat transfer between shell and tube side fluids.

Nowadays high prices of energy motive industry to apply energy methods, use of nanoparticles in conventional fluids have been considered to enhance heat transfer. Some authors have evaluated the effect of adding nanoparticles to base fluid in heat exchanger[5-8]. For instance Farajollahi et al[5] employed $\mathrm{Al}_{2} \mathrm{O}_{3}$ and $\mathrm{TiO}_{2}$ nanofluids in a shell and tube heat exchanger.

As a study on the effect of the baffle, Elias et al. [9]investigated the effect of different nanoparticle shapes (e.g., cylinders, bricks, blades, and platelets) on the overall heat transfer coefficient, heat transfer rate, and entropy generation of the shell and tube heat exchanger with different baffle angles and segmental baffle. They found that the heat transfer rate for every nanoparticle shape is higher for 20 baffle angles.

However, only a few Authors have described the velocity vectors using a video camera[1], X-rays[2], 
a designed pitot tube[3] and a commercial programme [4]. Recently, Xesus Nogueira et al. [10] conducted numerical and experimental studies on the oscillatory flow within a baffle tube that contains tri-orifice baffles using PIV(particle image velocimetry. Their findings showed that a numerical scheme is suitable for computation in complex flow situations. As a other work, Chang et al. [11, 12] lately performed numerical and experimental studies to investigate the effect of vertical baffles and the spiral baffle. Their results showed that particles with swirl for the parallel flow have two more recirculations in case of the spiral baffle.

When twisted tapes, spiral baffle plates and helical tapes are used for heat exchangers, velocity profiles will be entirely changed along the inner tubes. Until now, a lot of papers are included the researched works with and without nanofluids to improve heat transfer for heat exchanger. But there are few studies mentioned about velocity profiles near the baffles.

In this work, as a fundamental research for developing a shell and tube heat exchanger, local velocity profiles are studied with and without one inner tube, such as the entry, between and the outlet of the helical baffle plates in a horizontal circular tube using stereo PIV and Fluent.

\section{Experimental Procedure}

\subsection{Experimental apparatus}

Fig. 1 shows the layout of the experimental setup and stereo PIV system employed in this study. The experimental apparatus is indicating in Fig. 2 with helical baffle plate and one inner tube. Fig. 3 is showing the photograph of the experimental apparatus. This experimental testing tube is manufactured with an acrylic pipe $(d=64 \mathrm{~mm}, L=1000 \mathrm{~mm}$, thickness $=3.0 \mathrm{~mm})$ with and without one inner tube. The each of helical baffle with a thickness of $3 \mathrm{~mm}$ and a diameter of $64 \mathrm{~mm}$ is installed in the test tube with its length $240 \mathrm{~mm}$. This helical baffle is located at the center of the test tube $(X=380 \mathrm{~mm}$ from the entrance of the test tube). The detail schematic diagram of the helical plate is shown in Fig.3.

The flow rate was measured using a flow meter installed at the inlet of the main tube. The measurement region $X$ is the horizontal direction of the tube, $Y$ the vertical direction, and $Z$ the out-ofplane direction. Given that the test tube was circular, the images captured by the two cameras were significantly distorted. Thus, a square $\operatorname{box}\left(850^{\mathrm{L}} \times 100^{\mathrm{W}} \times 180^{\mathrm{H}}\right)$ was installed outside the circular tube, and the empty space between the circular tube and the square box was filled with water to reduce the distorting effect.

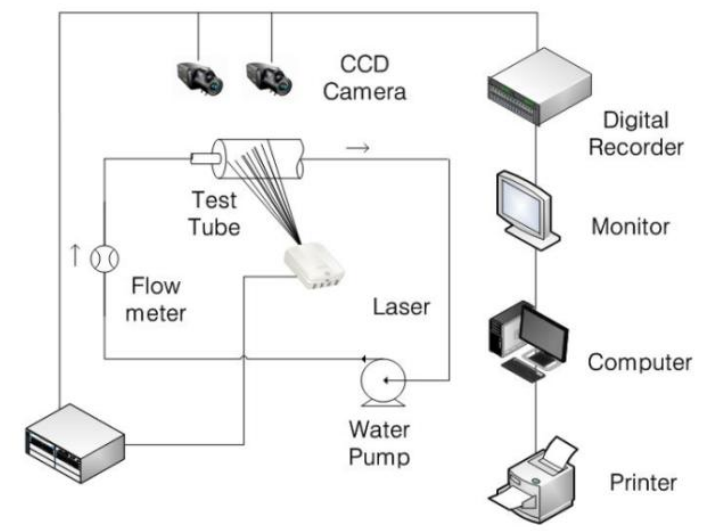

Fig1. Layout of the experimental setup and the stereo PIV system

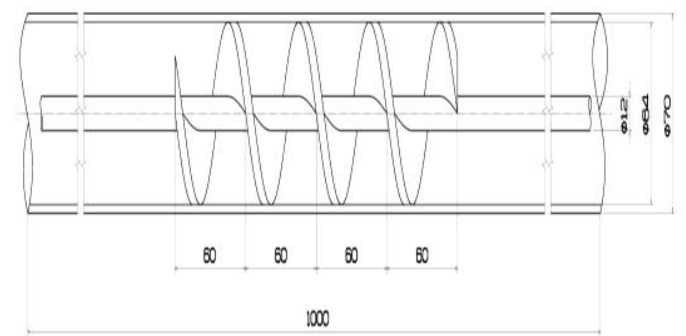

Fig2. Schematic diagram of the experimental apparatus with the helical baffle and the inner tube 


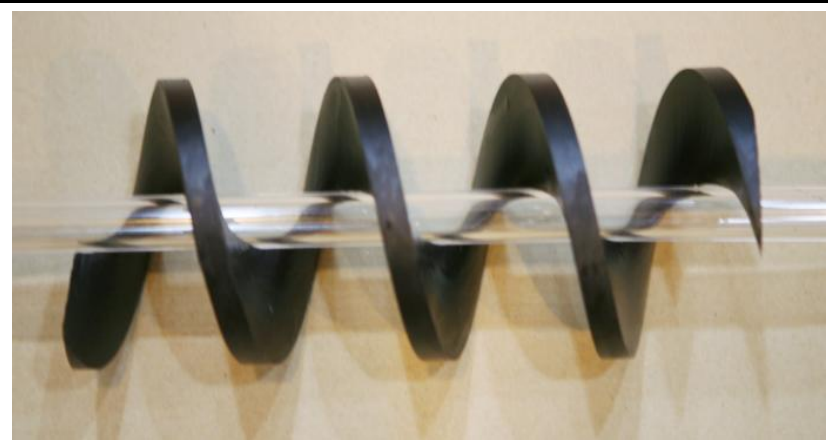

Fig3. Photograph of the helical baffle plate with one inner tube

\subsection{PIV measurement}

Two digital high-speed cameras (Basler $2.3 \mathrm{k} \times 1.7 \mathrm{k}$, $250 \mathrm{fps}$ ) with lenses (60 mm; MICRO NKKOP) were used for the stereoscopic measurements and were arranged as shown in Fig. 1. The flow field was visualized with a continuous laser light sheet (thickness $=2 \mathrm{~mm}$ to $3 \mathrm{~mm}$ ) (Ar ion laser, $2 \mathrm{~W}$ ). The two cameras were horizontally installed and maintained at $30^{\circ}$ angles toward the measurement area. The seeding particles (nylon, $\rho=997 \mathrm{~kg} / \mathrm{m}^{3} . d=100 \mu \mathrm{m}$ ) were suspended in the working fluid (water) for PIV measurements and were added at the entrance of the main pipe $(d=64 \mathrm{~mm}, L=1000 \mathrm{~mm})$.

\subsection{PIV Calculations}

To carry out three-dimensional measurements with the two camera system, camera calibration should be performed before main experiments. A test kit is manufactured using acryl materials for calibration, which has identical size of the test tube with water. This kit is indicating with a transfer equipment. The calibrator is a flat plate $(50 \mathrm{~mm} \times 50 \mathrm{~mm})$ on which grid lines are formed with regular intervals with $10 \mathrm{~mm}$ lines. This plate was traversed back and forth to the camera lens direction so that the grid images at six locations could be obtained. This plate was traversed inside of the test tube in order to consider refractive indexes of the working fluid (water) and the acrylic walls. To do this, a cover on the circular cylinder tube was installed. During the main experiments, this cover was completely closed so as not to make any leakage of water. The calibration method and threedimensional measurement algorithms developed by Doh et at.(2004)[12] were used for camera calibration and the Stereoscopic PIV measurements.

\section{RESULTS AND DISCUSSION}

1.1. Raw image of the particles at the entrance of the helical baffle

A PIV system is employed to measure the velocity profiles in horizontal circular tube with helical baffle plates with and without an inner tube at several places such as the entry, between and the outlet of the baffle. Fig. 4 is showing the raw image of particles between the entry of the helical baffle and the first baffle for $\mathrm{Re}=18,300$. The particles are slowly moving with some inclined flow angles at the entrance of the helical baffle. But, near the centerline of the baffle and after the baffle, the flow angles are increased along the gap of the baffle.

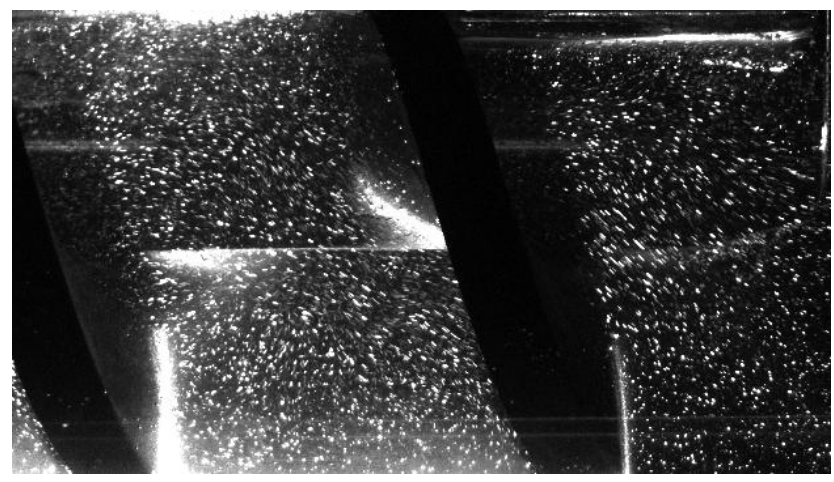

Fig4. Raw images between the helical baffle plates without the inner tube for $R e=18,300$ 


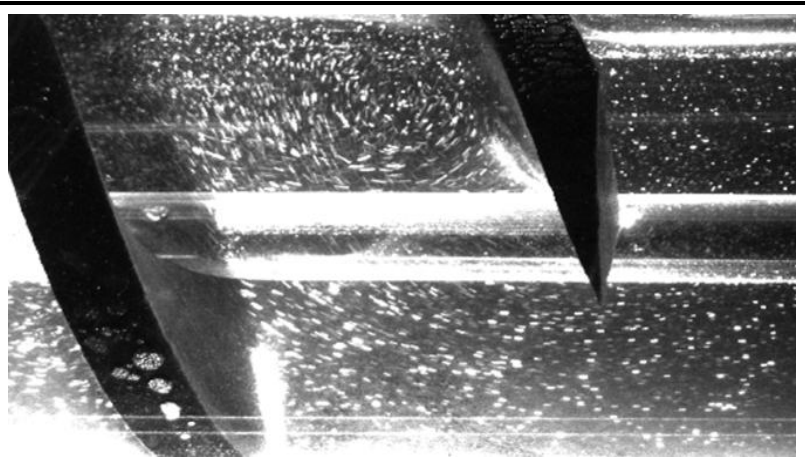

Fig5. Raw images between the helical baffle plates with an inner tube for $R e=18,300$.

Fig. 5 is showing raw image of the particles with the helical baffle with an inner tube for $\operatorname{Re}=18,300$. At the entrance of the helical baffle and the inner tube, the movement of particles is nearly uniform, but after the first baffle, the moving of particles are gradually fast. But, there are big recirculation of particles upside of the inner tube. These special features are considered of the effect of the inner tube between the two baffles.

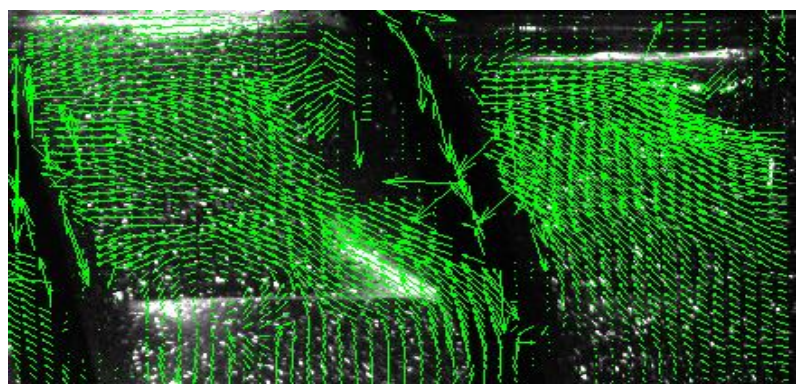

Fig6. Velocity vector field between the helical baffle plates without the inner tube for Re=18,300.

Fig. 6 is presenting velocity vector field between the helical baffle plates without the inner tube for $\mathrm{Re}=18,300$. This result is calculated from Fig. 4, which is the raw images between the helical baffle plates without an inner tube for $\mathrm{Re}=18,300$. The velocity vectors at the entry are shifting with some gradient flow angle. But, between the first baffle, the velocity vectors are moved slightly different profiles. There is a small recirculation zone near the centerline of the helical baffle. It is supposed that this feature is related to moving of particle's flow near the centerline and then this moving is going through next helical baffle.

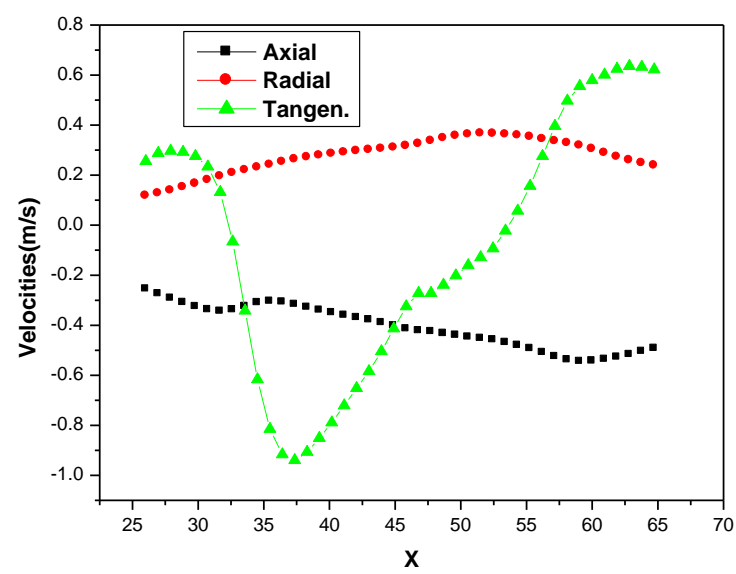

Fig7. Local Velocity profiles at the entry of the helical baffle plates without the inner tube for $\operatorname{Re}=18,300$.

Fig. 7 presents the local velocities at the entry of the helical baffle plates without the inner tube for $\mathrm{Re}=18,300$. As important things, the tangential components are slightly so strong at the entry and between the two baffles. These things are regarded with producing swirling flow at the entry of the helical baffle plates. But the axial and radial components are nearly zero or negative value, which are usually showed at the strong intensity of swirl in a circular tube. 


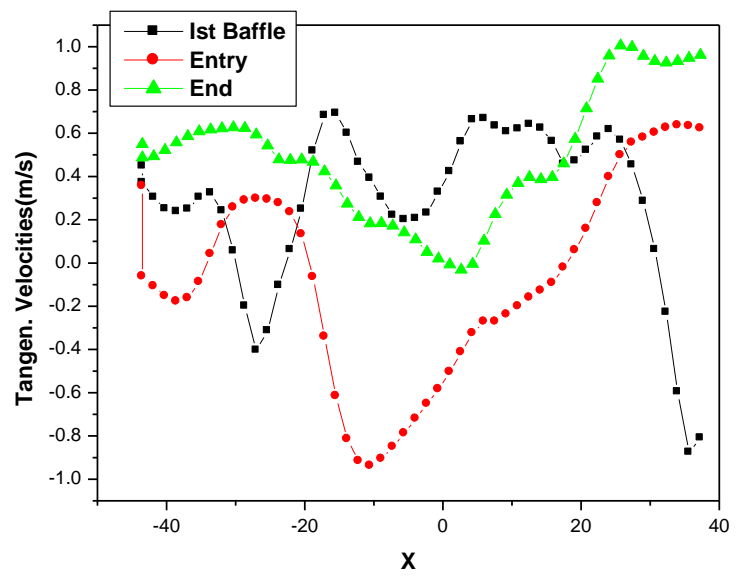

Fig8. Local tangential Velocities profiles along the helical baffle without the inner tube for Re=18,300.

Local tangential velocities are showing in Fig.8, comparing with the location of the entry, the first and the end of the helical baffle without the inner tube for $\operatorname{Re}=18,300$. The local tangential velocities are increased along the helical baffle. But at the end of the baffle, tangential velocities profiles are slightly decayed along the test tube.

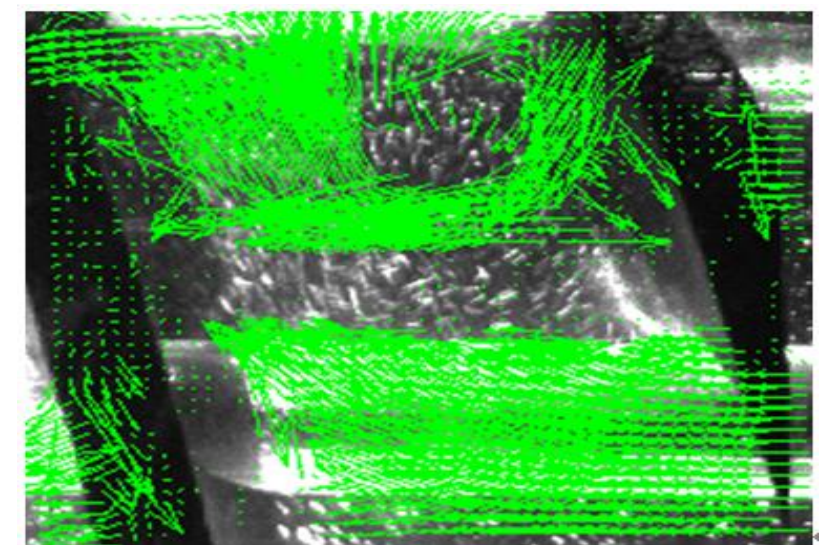

Fig9. Velocity vector field between the helical baffle plates for $\operatorname{Re}=18,300$.

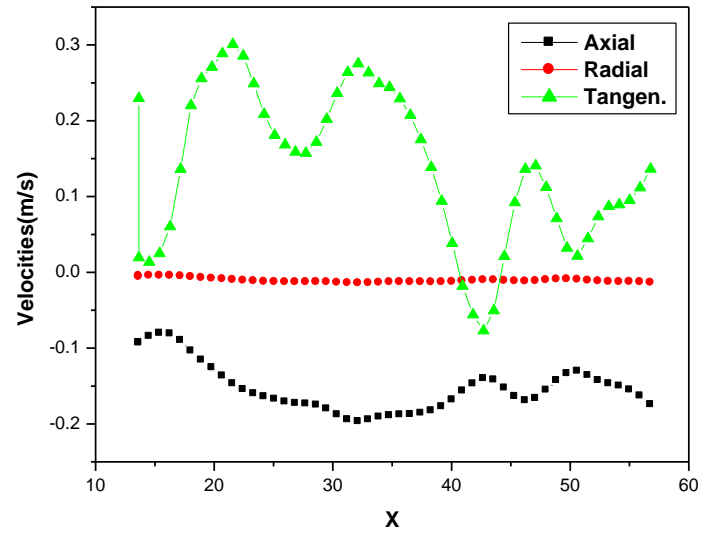

Fig10. Local velocity profiles at the entrance and the first of helical baffle plates with an inner tube for $R e=17,530$.

Fig. 10 shows the local velocities results to be calculated from the velocity vector in Fig. 9 for $\operatorname{Re}=8300$ at the entry of the helical baffle with one inner tube. The local axial and radial velocities are not much changed along the helical baffle. On other hand, the tangential components have a pronounced effect upside of the inner tube. It is considered to be the consequence of the helical baffle and an inner tube 


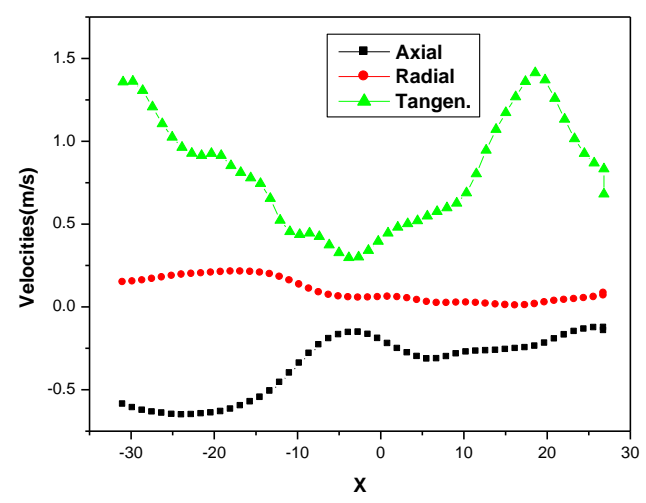

Fig11. Local velocity profiles between the first helical baffle plates with an inner tube for Re=17,530.

In case of the first baffle, the local velocities are illustrated in Fig. 11 for $\mathrm{Re}=17,530$. The tangential values are slightly stabilized between the first baffle than that of the entrance. It is showed three strong peaks of tangential components. But, the local axial and radial velocities are not much affected with the helical baffle and the inner tube.

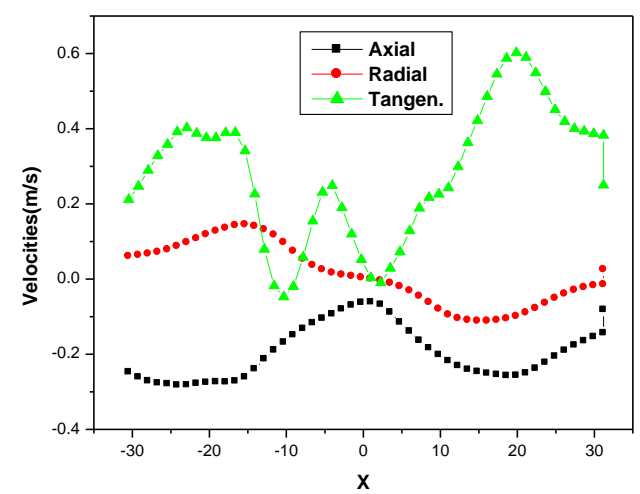

Fig12. Local velocity profiles between the second helical baffle plates with an inner tube for $\operatorname{Re}=17,530$.

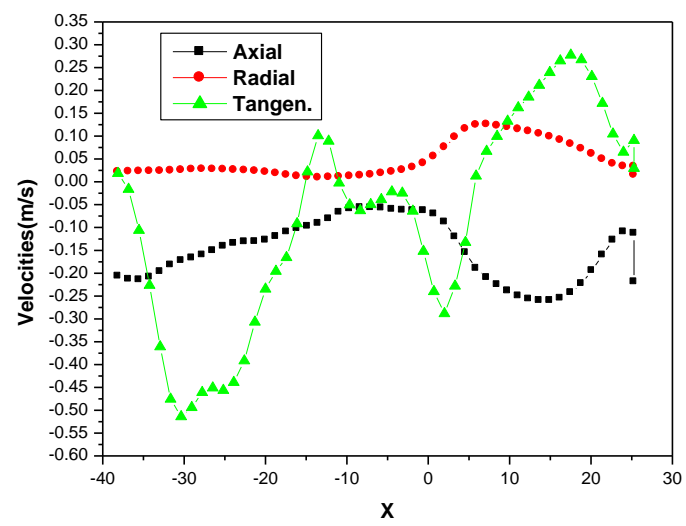

Fig13. Local velocity profiles at the end of the helical baffle plates with an inner tube for $R e=17,530$.

In Fig. 12 and Fig. 13, an interesting flow patterns are revealed between the second helical baffle and the end of it. The tangential velocities are presented balanced five strong peaks values between the second and the end baffle except one value in entry. In additional, axial and radial components are affected by the tangential components value.

However, in Fig. 13, the tangential velocities are distorted and decaying along the distance of the test tube at the end of the helical baffle. It is regarded as removing the helical baffle in the test tube. But the axial and radial values are not much changed along the distance. 


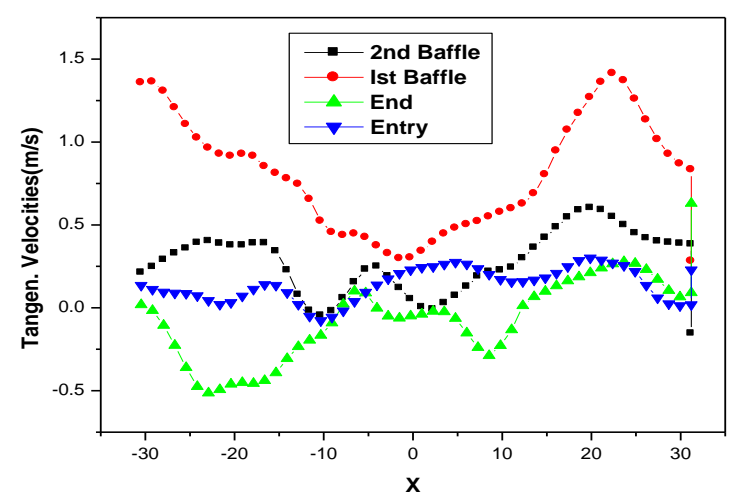

Fig14. Local tangential velocity profiles with the helical baffle plates with the inner tube along the test tube for $\operatorname{Re}=17,530$.

Tangential velocities are compared with these of several locations such as entry, the first, second and the end of the helical baffle in Fig. 14. The tangential components at the first baffle are showing the strongest values and then the components are decayed along the helical baffle. It is related the flow friction between the distance of the helical baffles. This particular thing will be affected that the efficient heat transfer is generated at a shell and tube heat exchanger.

\section{Numerical Works}

Numerical study is carried out to for finding the effect of the continuous helical baffle using Fluent. Fig. 15 is showing the velocity vectors between helical baffles without the inner tube for $R e=17530$. These velocity vectors indicate that the vectors are moving very fast with some flow angle at the entry of the baffle and then these flow produced a week recirculation zone behind of the first baffle. This feature is considered to be the effect of the helical baffle. This feature continues on next baffles along the test tube. But the strength of this flow is reduced with baffles. This is regarded as the flow friction between by the barrier of the continuous helical.

Fig. 16 present the velocity vectors with the continuous helical baffle with an inner tube for $\operatorname{Re}=18000$. There are similar to that of without inner tube, but the strong recirculation zone is indicated behind the first baffle. These results are regarded as the effect of the inner tube and the baffles.

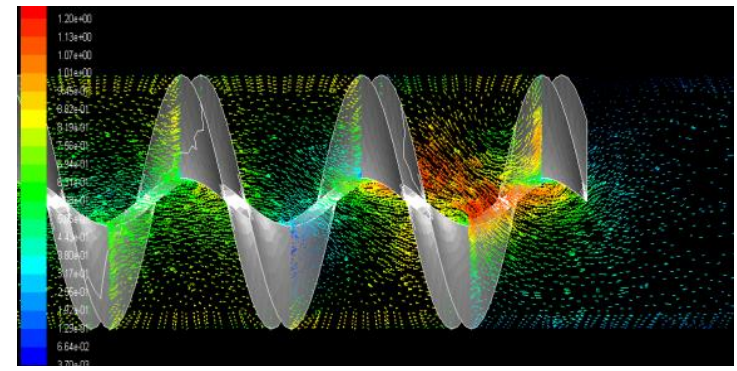

Fig15. Velocity vectors along a helical baffle without the inner tube for $R e=18,300$.

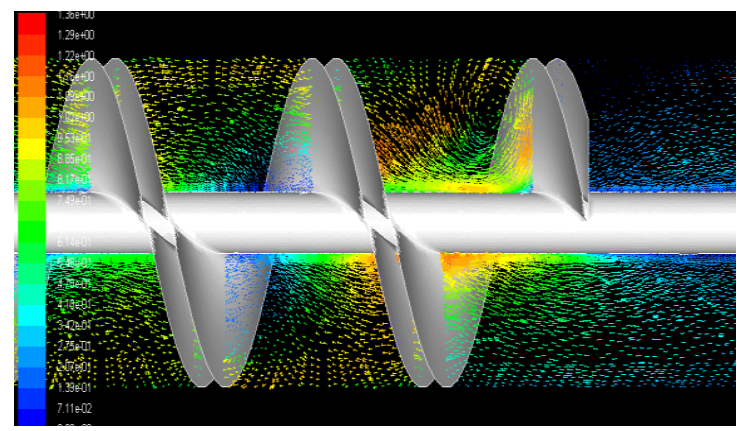

Fig16. Velocity vectors along a helical baffle with an inner tube for Re=17,530. 


\section{Conclusions}

This study has been performed to get the velocity information at the entry, between and the outlet of the continuous helical using the PIV technique and Fluent for numerical model. Through the experimental and numerical results, the following conclusions were drawn which are summarized below.

1. There is a small recirculation zone near the centerline of the helical baffle without the inner tube. It is supposed that this feature is related to moving of particle's flow near the centerline and then this moving is going through next helical baffle.

2. There is a big recirculation of particles upside of the inner tube with the continuous helical baffle and this thing is followed recirculating vector zone behind the baffle.

3. The tangential components are slightly so strong at the entry and between the two baffles without the inner tube. These things are regarded with producing swirling flow at the entry of the helical baffle plates. But the axial and radial components are nearly zero or negative value, which are usually showed at the strong intensity of swirl in a circular tube.

4. The tangential components at the first baffle with the inner tube are showing the strongest values and then the components are decayed along the helical baffle. This thing is regarded as the flow friction between by the barrier of the continuous helical.

5. Numerical velocity vectors without the inner tube are showed that these flow produced a week recirculation zone behind of the first baffle. In case of the inner tube, the feature are similar to that of without inner tube, but the strong recirculation zone is indicated behind the first baffle and the inner tube. These results are regarded as the effect of the inner tube and the baffles.

\section{ACKNOWLEDGEMENT}

This research was supported by the Re SEAT program funded by the Ministry of Science, ICT and Future Planning through the National Research Foundation of Korea and the Korea Lottery Commission grants.

\section{REFERENCES}

[1] B.B. Gupta, J.A. Howell. D. Wu, R. W. Field, "A helical baffle for cross-flow microfiltration", Journal of Membrane, 1995, 99, pp. 31 42.

[2] J. J. van Dijk, A.C. Hoffmann, D. Cheesman, J. G. Yates, The influence of horizontal internal baffles on the flow pattern in dense fluidized beds by X-ray investigation, Power Technology, 1998, 98, pp. 273 278.

[3] Halfdan Knudsen, "Investigation of a novel helical flow shell and tube heat exchanger", Heat Transfer 1998, Proceedings of $11^{\text {th }}$ IHTC, Vol.6, August 23-28, 1998, Kyongju, Korea, Vol. 6, pp. 293 298.

[4] Young-Seok Son, Jee-Young Shin, "Performance of a shell and tube heat exchanger", KSME International Journal, 2001, Vol. 15, No.11, pp.1555 1562.

[5] B. Farajollahi S. Gh. Etemad, M. Hojjat, "Heat transfer of nanofluids in a shell and tube heat exchanger", International Journal of Heat and Mass Transfer 53(2010) pp. 12 17.

[6] A. Zamzamian, S. NasseriOskouie, A. Doosthoseini, AI Joneidi, M. Pazouki, "Experimental investigation of forced convection heat transfer coefficient in nanofluids of $\mathrm{Al}_{2} \mathrm{O}_{3} \mathrm{O}_{3} / \mathrm{EG}$ and $\mathrm{CuO} / \mathrm{EG}$ in a double pipe and plate heat exchanger under turbulent flow", Experimental Thermal and Fluid Science 35(2011) pp. $495 \sim 502$.

[7] W. Duangthongsuk, S. Wongwises, "Heat transfer enhancement and pressure drop characteristics of TiO2-water nanofluids in a double pipe counter flow heat heat exchanger", Journal of Heat and Mass Transfer 52 (2009) pp. 2059 2067.

[8] M.N. Pantzali, A.A. Mouza, S.V. Paras, "Investigating the efficacy of nanofluids as coolant in plate heat exchanger(PHE)", Chemical Engineering Science 64 (2009) pp. 3290 3300.

[9] M.M. Elias, I.M. Shahrul, I.M. Mahbubul, R. Saidur, N.A. Rahim, "Effect of different nanoparticle shapes on shell and tube heat exchanger using different baffle angles and operated with nanofluid" International Journal of Heat and Mass Transfer, 2014, Vol. 70, pp. 289 297. 
[10] Xesus Noguerira, Benjamin J. Taylor, Hector Gomez, Ignasi Colominas, Malcolm R. Mackley, "Experimental and computational modeling of oscillatory flow within a baffled tube containing periodic-tri-orifice baffle geometries", Computers and Chemical Engineering, 2013, 49, pp. $1 \sim 17$.

[11] Tae-Hyun Chang, Hae-Soo Lee, Keon-Je Oh, and Chang-Hoan Lee, Doh, D.H, "Velocity profiles between two baffles in a horizontal circular tube", Journal of Thermal Science, 2014, Vol. 23, pp. 544 551.

[12] Tae-Hyun Chang, Hae-Soo Lee, Keon-Je Oh, and Chang-Hoan Lee, "Study on Velocity Profiles around the Spiral Baffle Plates in a Horizontal Circular Tube without inner Tubes", The $13^{\text {th }}$ Asian Symposium on Visualization June 22-26, 2015, Novosibirsk, Russia.

[13] Cho, G.R., Kawahashi, M., Hirahara, H. and Kitadume, M., "Application of stereoscopic particle image velocimetry to experimental analysis of flow through multiblade fan. JSME International Journal Series B", 2005, Vol. 48, No. 1, pp. 25-33.

[14] Yong-Gang Lei, Ya-Ling He*, Rui Li, Ya-Fu Gao, "Effects of baffle inclination angle on flow and heat transfer of a heat exchanger with helical baffles", Chemical Engineering and Processing 47 (2008) pp. 2336-2345 